\title{
Significance of the Structure of Human Skeleton
}

\author{
Mohammad Abul Hossain* \\ Professor, Department of Chemistry, University of Dhaka, Dhaka-1000, Bangladesh \\ *Corresponding author: hossainabul@yahoo.com
}

\begin{abstract}
This study presents the physical analysis of the structural morphology of the human skeleton at different side views. In this investigation, whole of the human skeleton system was divided into five groups of bones: skull, rib cage, pelvic girdle, lower limb and upper limb. The physical analysis of the shapes of initial four groups of bones provided looks like the four letters of the Arabic language namely Mim, Ha, Mim and Dal, respectively. Interestingly, combination of these four letters makes the Arabic word "Muhammad, محمد (peace be upon him: PBUH)" which is the name of the best person in the universe, according to the Muslims. The observation is very clearly presented at the left side view of the human skeleton. Again, the physical analysis of the structure of bony framework of each hand in the upper limb of human skeleton as elucidated here shows the combination of four other Arabic letters: Alif, Lam, Lam and Haa, leading to making the Arabic word "Allah, للد". Analytical observations in both cases are schematically presented in the article. Thus the structure of human skeleton represents two Arabic words which are very significant in the religion of Islam.
\end{abstract}

Keywords: human skeleton, structure, Arabic words Muhammad and Allah

Cite This Article: Mohammad Abul Hossain, "Significance of the Structure of Human Skeleton." American Journal of Medical Sciences and Medicine, vol. 6, no. 1 (2018): 1-4. doi: 10.12691/ajmsm-6-1-1.

\section{Introduction}

There are different histories about the development of human beings. But it is known to all, humankind is the topmost creation in the universe. From the beginning, humans have been trying to develop in knowledge as well as cultivate themselves. The study of human beings probably started in ancient Greece (Ptolemaic Kingdom in 300 BC, Alexandria was the Capital) [1]. Greek physician Herophilus, living in Alexandria, was the first anatomist, who explored the flow of blood from the heart through the arteries, in his book titled Midwifery, which discussed the duration and phases of childbirth $[2,3,4]$. Later, Alexandria became a center of anatomy under Islamic rule, with Ibn Zuhr (1094-1162), a notable Muslim Arab physician, surgeon and poet working there $[5,6]$. Human anatomy can be defined as the morphology of human body which consists of organs, tissues and cells.

From the development of modern science, we knew that the human body is composed of many different types of nearly 37 trillion $\left(3.72 \times 10^{13}\right)$ cells that together create 4 types of tissues and subsequently 11 organ systems [7]. These organ systems include the integumentary system, muscular system, skeletal system, lymphatic system, respiratory system, digestive system, nervous system, endocrine system, cardiovascular system, urinary system, and reproductive systems.

The study of human anatomy is part of the study of the form and structure of organisms and their specific structural features. Cell is the unit of human body which is composed of 65 percent to 90 percent of water. The chemical composition of all the organ systems of the average adult human body are water (65-90\%), minerals $(6 \%)$, fat (variables), protein $(16 \%)$, carbohydrates $(1 \%)$ and nucleic acids (1\%). Eleven elements account for $99 \%$ of the mass of average human body and the other $1 \%$ is made up of trace elements [8]. These are Oxygen (65\%), Carbon (18\%), Hydrogen (10\%), Nitrogen (3\%), Calcium $(1.5 \%)$, Phosphorus (1.2\%), Potassium (0.2\%), Sulfur ( $0.2 \%)$. Chlorine $(0.2 \%)$, Sodium $(0.1 \%)$ and Magnesium $(0.05 \%)$ of body mass. Other trace elements are iron, cobalt, copper, zinc, iodine, selenium, fluorine, aluminum, silicon, etc [9]. Recently, we have come to know, the average $70 \mathrm{~kg}$ adult human body contains approximately $7 \times 10^{27}$ atoms and contains at least detectable traces of 60 chemical elements [10]. About 29 of these elements are thought to play an active positive role in life and health of humans $[8,9]$.

On the other hand, the musculoskeletal system of a human body is an activity organ system that gives humans the ability to move using their muscular and skeletal systems. The musculoskeletal system provides structure, support, stability, and movement to the body. It is made up of the muscles, bones of the skeleton, cartilage, tendons, ligaments, joints, and other. Figure 1 shows the muscular system of human body at different side views [11]. The human body's muscular system consists of about 650 muscles that aid in movement, blood flow and other bodily functions. Skeletal system is the system of bones, associated cartilages and joints of the human body. Together these structures form the human skeleton. Skeleton can be defined as the hard framework of human body around which the entire body is built. Joints are very important because they make the hard and rigid skeleton, allow different types of movements at different locations. 

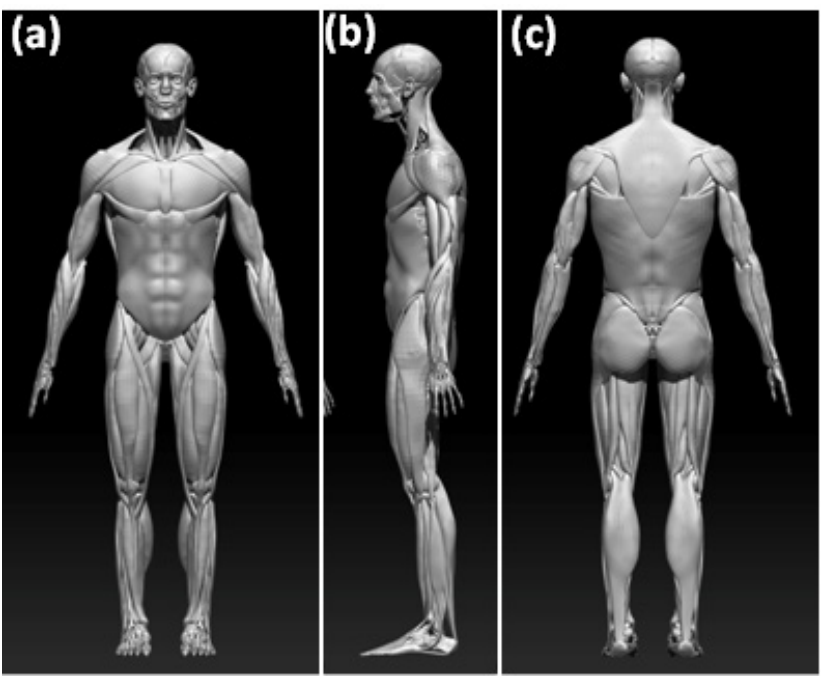

Figure 1. Muscular system block-out of human male: (a) Anterior (front side) view, (b) left side view and (c) Posterior (back side) view (Jason Holt, 2014 [11])

The human skeleton is the internal framework of the body. It is composed of around 270 bones at birth- this total decreases to around 206 bones by adulthood after some bones get fused together $[12,13,14]$. The human skeleton can be divided into the axial skeleton ( 80 bones) and the appendicular skeleton (126 bones). The axial skeleton is formed by the vertebral column (26 bones), the rib cage ( 25 bones), the skull (28 bones) and other associated bone ( 1 bone). The appendicular skeleton which is attached to the axial skeleton, is formed by the shoulder girdle ( 4 bones), the pelvic girdle ( 2 bones) and the bones of the upper limb (60 bones) and lower limb (60 bones) [14].

The human skeleton is not as sexually dimorphic but subtle differences between sexes in the morphology of the skull, dentition, long bones, and pelvis exist. In general, female skeletal elements tend to be smaller and less robust than corresponding male elements within a given population [15]. The human female pelvis is also different from that of the males in order to facilitate childbirth [16]. The human skeleton performs six major functions: support, movement, protection, production of blood cells, storage of minerals, and endocrine regulation. Thus the skeleton is very important for survival of human beings. The present study was undertaken to investigate the structural morphology of human skeleton from the view point of physical observation and elucidate its significance.

\section{Methodology}

The structure of human skeleton was physically investigated in the Anatomy Department of Dhaka Medical College Hospital, Dhaka University, Dhaka, Bangladesh. Several pictures of human skeleton were taken at different side views with the help of Professor Dr. Shamim Ara, Head of the anatomy department of the college, and her colleagues. The pictures of the structure of human skeleton were analyzed with different point of views and performed modeling of different observations. In the study, the skeleton was divided into five groups of bones: skull, rib cage, pelvic girdle, lower limb and upper limb. The structural morphology of each group of bones was investigated at different view points and their observations are schematically presented in respective figures.

\section{Results and Discussion}

The human skeleton is a living, dynamic structure, which serves as a supporting and protective framework for the body. Figure 2 shows the skeleton system of human body at different point of views: (a) anterior (front side) view, (b) left side view and (c) posterior (back side) view. The physical structural view of human skeleton was investigated in five groups of bones which are presented in Figure 3(a). Observations are schematically presented in Figure 3(b) and Figure 4.

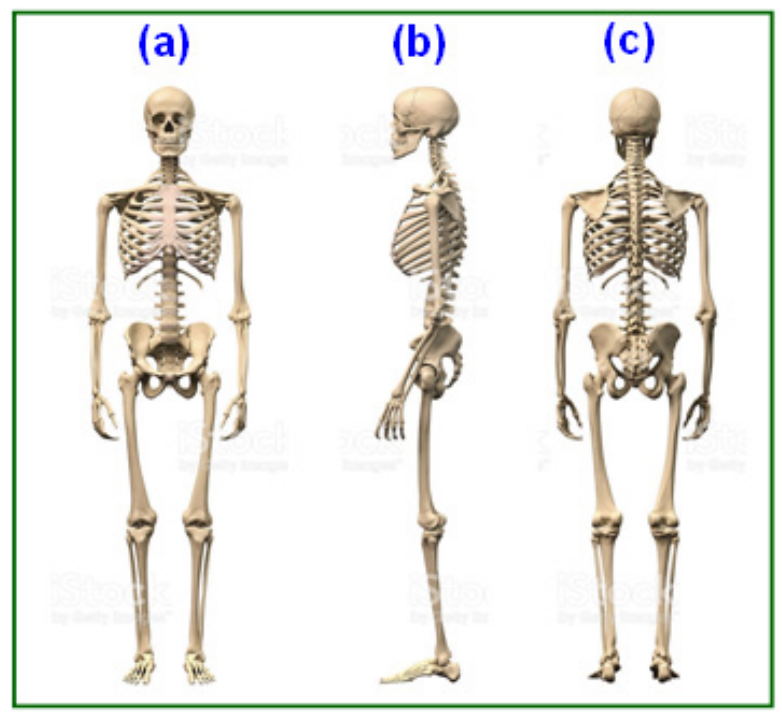

Figure 2. Bone structure and skeletal system of human body (a) Anterior (front side) view, (b) Left side view and (c) Posterior (back side) view (iStock by Getty Images [17])

(b)

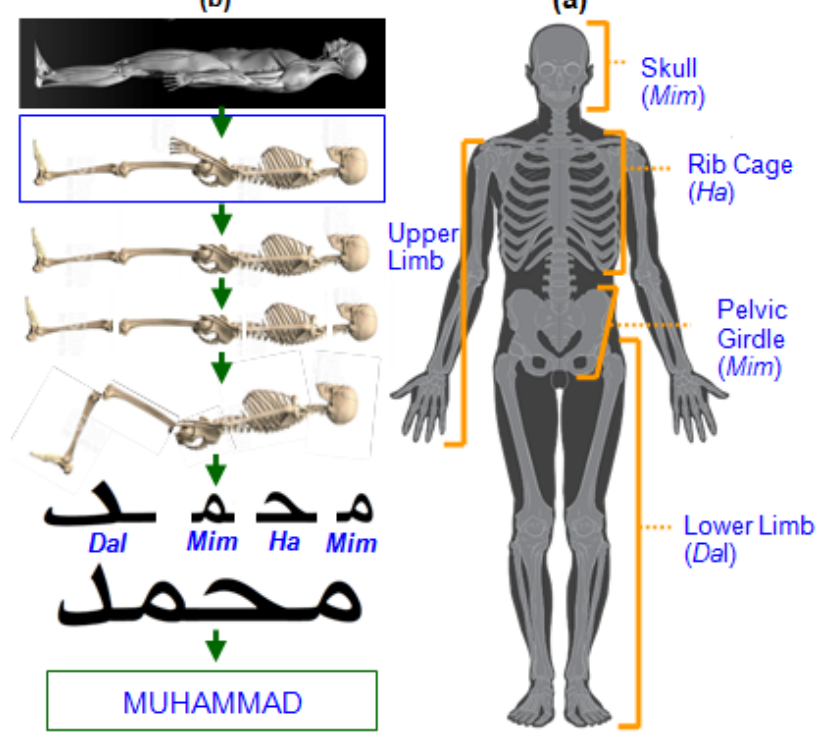

Figure 3. (a) Five groups of bones in human skeleton; (b) Left side view of human skeleton represents the Arabic word Muhammad (PBUH): Skull (head) for Mim ( $\mathbf{0})$, Rib cage (chest) for $\mathrm{Ha}$ (ح), Pelvic girdle

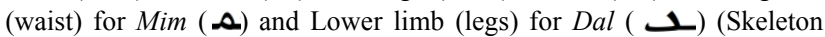
pictures used from iStock by Getty Images [17]) 


\subsection{First Group Bones: Skull}

The skull or head is the first group of bones which is made by 28 bones of different sizes and shapes. Combination of 28 bones makes it a nearly spherical shape with empty space inside. The physical observation of the left side view of skull is like the Arabic letter $\operatorname{Mim}(\boldsymbol{0})$.

\subsection{Second Group Bones: Rib Cage}

The rib cage or chest is the second group of bones which is made by 12 paired ribs and a sternum bone. Combination of 25 bones makes it a mild cone shape with empty space at inside, physically which looks like as the Arabic letter $\mathrm{Ha}$ (ح).

\subsection{Third Group Bones: Pelvic Girdle}

The pelvic girdle or waist is the third group of bones which is made by a trigonal sacrum bone and 2 coxa bones of half-spherical similar sized. Combination of these 3 bones makes it a nearly spherical shape with a cavity at inside which is physically looks like the Arabic letter $\operatorname{Mim}(\boldsymbol{\alpha})$.

\subsection{Fourth Group Bones: Lower Limb}

The lower limb is the fourth group of bones which is made by 60 bones of different shapes and sizes described previously. Combination of a long size Femur, Tibia, Fibula and small sizes 1 Patella, 7 Tarsals, 5 Metatarsals and 14 Phalanges, make a vent shaped structure like as the Arabic letter Dal (1) at different conditions.

In this observation, it is very clear that in human skeleton of Figure 3(a): the shapes of the skull, the rib cage, the pelvic girdle and the lower limb are like as the Arabic letters

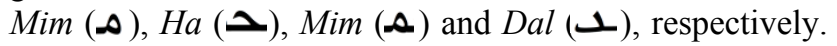
The left side view of human skeleton in Figures 2(b) and 3(a) show such observation is very clear which is schematically presented in Figure 3(b). Thus the combination of axial skeleton (skull and rib cage) with the pelvic girdle and lower limbs provided the structure of the Arabic word "Muhammad, محمد (peace be upon him: PBUH)".

\subsection{Fifth Group Bones: Upper Limb}

Moreover, the physical structural view of each hand in upper limb; bony framework of the each hand (combination of carpals, metacarpals and phalanges; made by 27 bones) represents four Arabic letters. Here, the shape of $5^{\text {th }}$ finger (Little finger; made by 1 metacarpal and 3 phalanges) is like the Arabic letter Alif (1), the $4^{\text {th }}$ finger (Ring finger; made by 1 metacarpal and 3 phalanges) is like the Arabic letter $\operatorname{Lam}(\mathcal{J})$, the $3^{\text {rd }}$ finger (Middle finger; made by 1 metacarpal and 3 phalanges) is like the Arabic letter Lam $(\boldsymbol{l})$ and the $2^{\text {th }}$ finger (Index finger; made by 1 metacarpal and 3 phalanges) along with $1^{\text {st }}$ finger (Thumb; made by 1 metacarpal and 2 phalanges) is like the Arabic letter Haa (d). Eight carpals of each hand act as the basement of all fingers which is like the coordinator of the four letters. As a whole the physical structure of each hand represents the Arabic word Allah
(الله ) which is the combination of the above mentioned 4 letters, schematically shown in Figure 4. The other parts ( 3 bones) of upper limb: one humerus, one radius and one ulna, act as the connector of the words Allah to Muhammad (PBUH) in the human skeleton.

Thus the structure of human body is like the constructed combination of two Arabic words Muhammad (PBUH) and Allah. The Arabic words Muhammad (PBUH) and Allah are very important in Islamic history. In Islam, Allah is the creator of the whole universe and Muhammad (PBUH) is the messenger (last prophet) of Allah. The meaning of the Arabic word, Muhammad (PBUH) is praiseworthy.

Muhammad (PBUH) (570 - 632 AD) was an Arabian Prophet, best known as the central figure and founder of the Abrahamic religion of Islam and is amongst the most revered and important historical persons in the world. Muhammad (PBUH) was/is ranked as number 1 in Michael H. Hart's book "The 100: A Ranking of the Most Influential Persons in History" [18].

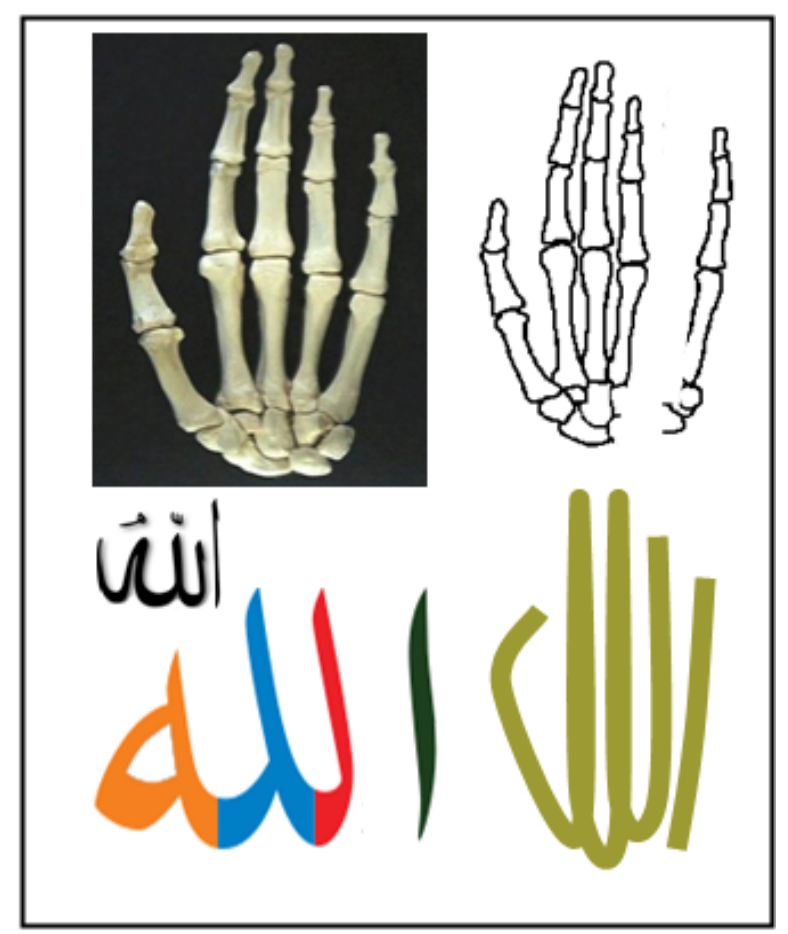

Figure 4. Structure of the human hand and bony framework of the hand represent the Arabic word Allah: $5^{\text {th }}$ finger for Alif ( 1$), 4^{\text {th }}$ finger for Lam ( $\rfloor), 3^{\text {rd }}$ finger for $\operatorname{Lam}(\downarrow)$, combination of $2^{\text {nd }}$ finger and thumb for Haa ( d)

\section{Conclusion}

The physical analysis of the structural morphology of the skeleton of human body elucidated that the left side view of human skeleton, except upper limb, is the representative of the Arabic word Muhammad (محمد) (PBUH). Again, the physical structure of the bony framework of each hand (combination of carpals, metacarpals and phalanges) in upper limb is like the Arabic word Allah ( الله (). Three other bones; humerus, radius and ulna, in upper limb are the connector of the two structural names of Allah and Muhammad (PBUH) in the human skeleton. Thus the structure of human skeleton represents the Arabic words Muhammad (PBUH) and Allah. 


\section{Acknowledgements}

The author is grateful to Sheikh Shahzada Professor Dr Ahmed Peyara Bagdadi (R), Shahpur Dargah Sharif, Comilla, Bangladesh for his kind inspiration to perform the study. The author wishes to acknowledge to Professor Dr. Shamim Ara, Head of the Anatomy Department, Dhaka Medical College Hospital, University of Dhaka, Bangladesh, and her colleague Professor Dr. Md. Rafiqul Alam, for their cooperation to take human skeleton pictures at different side views. The author is thankful to iStock by Getty Images and Jason Holt, 2014 for their support by supplying clear pictures of human skeleton. The author also thankful to Mr. Golam Gaus Al-Quaderi, Associate Professor of English Department, University of Dhaka, for his review of the manuscript. Finally, the author extends his thanks to his wife parents, wife Mrs. Shahzadi Rof Rof Peyaree, his daughters: Shadita, Sakira and Sakura for their support, suffering and understanding during the preparation of the manuscript.

\section{Conflict of Interest}

The author has no conflict of interest to declare.

\section{References}

[1] Stronk, J.P, Ctesias' Persian history: introduction, text, and translation, Wellem Verlag, Dusseldorf, Serbia 2010.

[2] Galen and Phillip, De Lecy. On Semen (trans.), Akademie Verlag, Berlin, 1992.
[3] Heinrich, V.S, Herophilus: the art of medicine in early Alexandria: edition, translation and essays, Cambridge University Press, 2nd ed. UK, 2004.

[4] Connell, S.M, "Aristotle and Galen on sex difference and reproduction: a new approach to an ancient rivalry," Studies in History and Philosophy of Science, 31(3), 405-427, 2000.

[5] Azar, Henry, The sage of seville: Ibn Zuhr, his time, and his medical legacy, American University in Cairo Press, 2008.

[6] Missori, P., Brunetto, G.M, Domenicucci, M. "Origin of the cannula for tracheotomy during the middle ages and renaissance," World Journal of Surgery, 36(4), 928-934, 2012.

[7] Eva, B., Allison, P., Federica, F., Alina, B., Raffaella, C., Flavia, F., Lorenza, V., Maria, C.P., Simone, T., Francesco, P., Soledad, P.A, Pierluigi, S. and Silvia, C. "An estimation of the number of cells in the human body," J Annals of Human Biology, 40(6), 463471, 2013.

[8] Nielsen, F.H. Ultratrace minerals: Modern nutrition in health and disease /editors, Maurice E. Shils. Baltimore: Williams \& Wilkins, 1999, 283-303.

[9] Chang, R. Chemistry. 9th ed. McGraw-Hill, 2007, 52-53.

[10] Thomas, J. National Accelerator Facility: Office of Science Education, 2017. education.jlab.org/faq/index.html.

[11] Jason Holt, 2014 human skeleton.

[12] Marshall, C.C. Mammal anatomy: an illustrated guide, New York: Cavendish Square, 2010, 129-132.

[13] Robert, J.M. Basic anatomy and physiology of the human body, First ed., John Wiley \& Sons, Inc. 1975, 87-88.

[14] Rod, R.S. Trent DS and Philip T. Anatomy and physiology. 2nd ed., Mosby Year Book Inc., 1992, 184-185.

[15] Michael, S., Erik, S., Udo, S. and Wayne, C. Thieme atlas of anatomy-internal organs., 2nd ed., 2006, 113-116.

[16] Clellan, S.F. and Frank, A.B. Patterns of sexual behavior harper \& row, New York, 1951.

[17] iStock by Getty Images: https://www.istockphoto.com/photo/ spin-of-a-human-skeleton-gm172953783-6808505.

[18] Michael, H.H. The 100: A ranking of the most influential persons in history, citadel press. Kensington publishing corp. New York: USA, 1992, 3-8. 